\title{
Traditional Chinese medicine in the treatment of postpartum bell's palsy
}

\begin{abstract}
Introduction: Pregnant women have more risk for Bell's palsy compared to non-pregnant women. The majority of cases occur in the third semester of the immediate period postpartum. In traditional Chinese medicine, Bell's palsy occurs due to the invasion of the external pathogenic factor Wind-Cold attacking the face's channel.
\end{abstract}

The purpose of this study is to demonstrate why women in post-partum period had more propensity to Bell's palsy and that the patient has chakras' energy deficiencies that leads to propensity to develop this problem.

Methods: through one case report, 36 years old women who had cesarean section in on November 14th 2020. She wakes up in the next day with the face completely deviated to the right side and cannot close her eyelid in the right eye. She searched for Western medicine physician that orientate her to intake corticosteroids. She went to the author's clinic and told the doctor that she always turns on the fan on top of her because she was felling much hot in her body during the pregnancy and after the partum. The treatment consisted in Chinese dietary counseling, auricular and systemic acupuncture. It was orientated to restart to intake the homeopathies, crystal based medications that was recommended to her one year ago, and she stopped to intake during the pregnancy.

Results: After the first acupuncture session, her face improved very well (50 percent) and she could smile and move the tongue, close her right eyelid better, and the deviation reduced completely using three acupuncture sessions. She also was orientated to avoid raw foods, cold water and walk barefoot and dry the hair after washing it and avoid to go outside her home during the guard period (for a period of 40 days).

Conclusion: Women in the post-partum period has more propensity to develop Bell's palsy because they lost very much Blood and other fluids during the child-birth and usually loose much energy in this process weakening the body and had more propensity to the invasion of Cold and Wind, generation in this form, Bell's palsy symptoms.

Keywords: postpartum, bell's palsy, external pathogenic factor, diet, energy, acupuncture, chakras, homeopathy, hippocrates
Volume 12 Issue 2 - 202 I

\author{
Huang Wei Ling \\ Infectious Diseases, General Practice, Nutrition, Acupuncture \\ and Pain Management Specialist, Medical Acupuncture and Pain \\ Management Clinic, Franca, Brazil
}

Correspondence: Huang Wei Ling, MD, Infectious Diseases, General Practice, Nutrition, Acupuncture and Pain Management Specialist, Medical Acupuncture and Pain Management Clinic, Rua Homero Pacheco Alves, 1929, Franca, São Paulo, 14400-010, Brazil, Tel (+55 16) 372I-2437, Email weilingmg@gmail.com

Received: March 12, 2021 | Published: March 26, 2021

\section{Introduction}

According to Western medicine, Bell's palsy is the title given to paralysis of the muscles of the face. It can be unilateral, partial or complete. It is stated that the majority of the patients present natural recovery within a month. ${ }^{1}$

The symptoms are more prompt to happen with patients aged 15 to 40 years old. Symptoms of loss of ability to taste and smell are associated with Bell's palsy physiopathology. ${ }^{2}$ The main symptoms are rapid onset of mild weakness to total paralysis on one side of the face occurring within hours to days. ${ }^{1}$

The risk of facial palsy for pregnant women is higher than for non-pregnant women. Most cases occur in the third trimester and the immediate postpartum period. Unilateral facial palsy is a commonly seen mono-neuropathy. ${ }^{3}$

In Western medicine, although the exact reason Bell's palsy occurs is not clear, it is often related to exposure to a viral infection. ${ }^{4}$

The current management of the disease aims to reduce inflammation to the facial nerve and/or preventing corneal complications. Protecting the cornea from excessive dryness and abrasions should be addressed by the clinician through proper patient education. Corticosteroids are constantly used to reduce inflammation. ${ }^{1-4}$
But, this presentation is based on the Hippocrates quotes that said that it is important to consider other ancient medical traditional prior to the knowledge we have nowadays and for this reason the author selected to write this article using traditional Chinese medicine reasoning, together to what with we have nowadays regarding Bell's palsy in the postpartum period. ${ }^{5}$

The condition that is congruent with Bell's palsy in traditional Chinese medicine is called "Zhong Feng - Zhong Jing Lao", which literally translates to "Wind attack the meridians." According to TCM, Bell's palsy is caused when the exogenous pathogenic Wind and Cold invade the meridians, muscles, and tendons of the face. ${ }^{6}$

\section{Purpose}

The purpose of this study is to demonstrate the reason why postpartum patients are more susceptible to have Bell's palsy, from the energy point of view and what the physician needs to know to prevent further events in the patients and to treat patients that have postpartum Bell's palsy.

\section{Methods}

Through and extensive search in articles in PubMed regarding post-partum Bell's palsy in Western medicine and in traditional Chinese medicine and through one case report of a patient that had post-partum Bell's palsy one day after child-birth. 


\section{Case report}

The case report that the author wants to share in this article is a 36-years-old woman who had symptoms of Bell's palsy one day after the child-birth.

She became pregnant in March 2020 and her daughter was born on November 13, 2020. During pregnancy and after the baby was born she felt very hot and still in the hospital she already took a shower, washed her hair and stayed with a fan and air conditioning on or the window open. The day after the birth of her daughter, around 8:30 PM she felt her tongue fall and when looking in the mirror, she saw that her entire right side of her face was crooked and that she could not close her right eye.

She looked for medical help and the physician prescribed the use of prednisone and said it would take about 3 months for her face to return to normal.

After some days without improving her symptoms, she went to the author's clinic.

In the past, she had sought the author's help because she was trying to get pregnant and was doing acupuncture sessions and replenishing her chakras' energy centers with highly diluted medications such as homeopathies as she was very weak in energy, demonstrated by the radiesthesia procedure. She said she was going also to another clinic to see the possibility of doing in vitro fertilization and after this conversation, she did not return any more to the clinic again, probably due to COVID-19 pandemic, during quite all 2020 only returning after she had the baby.

Her Chinese medicine diagnosis was Kidney Yang Deficiency, Kidney Yin deficiency, Blood deficiency and Heat retention.

Her treatment consisted in Chinese dietary counseling, orientating her to avoid all dairy products, raw foods, sweets and cold drinks. The author also advised her to avoid fried foods, eggs, honey, coconut, chocolate and alcoholic beverages. Also, coffee, soda and mate tea.

She also received auricular acupuncture, systemic acupuncture on the paralyzed spot associated with apex ear bloodletting, showed in the Figure 1.

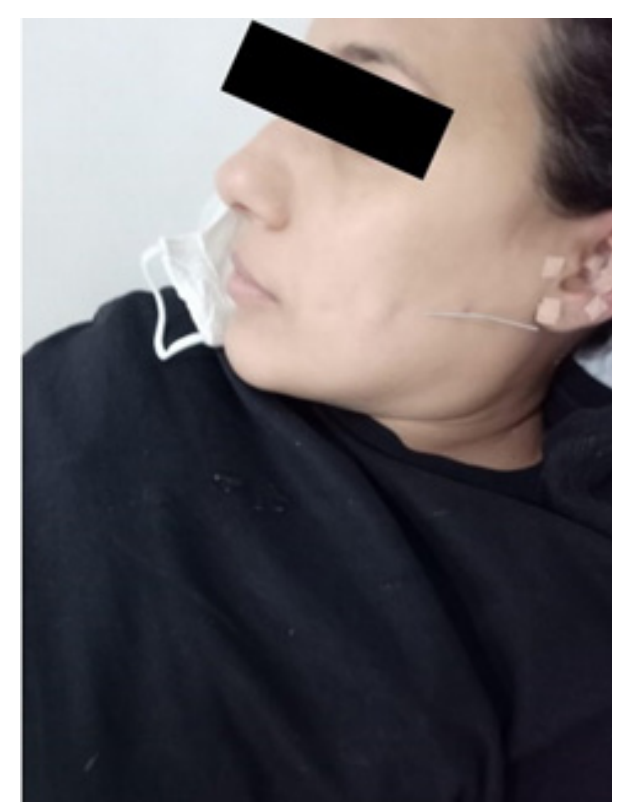

Figure I Patient case report in acupuncture session to treat Bell's palsy.

\section{Result of the case report}

After the first three acupunctures sessions, her face improved completely and now she can smile and move the tongue, close her right eyelid better, and the deviation disappeared entirely. In the Figure 2, you can see the photos of her before and after the treatment.
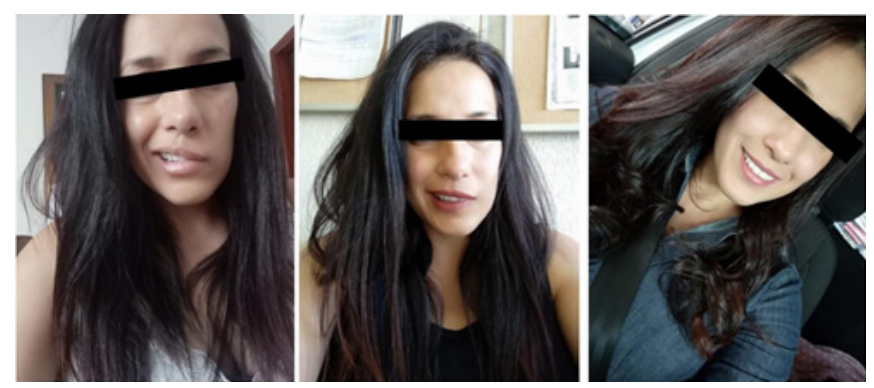

Figure 2 On the left and middle photos, you can see the Bell's palsy before the treatment and after three Acupuncture sessions, in the photo on the right side, the facial improvement completely.

\section{Discussion}

As the author mentioned in the introduction session, she wrote this article based on Hippocrates thoughts that said that it is more important to consider other ancient medical traditions; prior to the knowledge we have nowadays. ${ }^{5}$

For this reason, the author chose to explain how to prevent, treat patients with Bell's palsy after pregnancy using traditional Chinese medicine reasoning associating with what we have nowadays regarding this theme in the literature. ${ }^{5}$

The representation of a tree created by the author and published in many other article, illustrate on how diseases are treated today from the point of view of Western medicine and according to traditional Chinese medicine point of view. The importance of this metaphor is to show how Western and ancient medical perspectives could work together. The tree, illustrated on the Figure 3, has a trunk with several branches that represents each medical specialty. Coming out of each branch, you have many leaves that represent the symptoms and diseases treated by each medical specialty. In Western medical perspective, they are treating the leave level. ${ }^{7-16}$

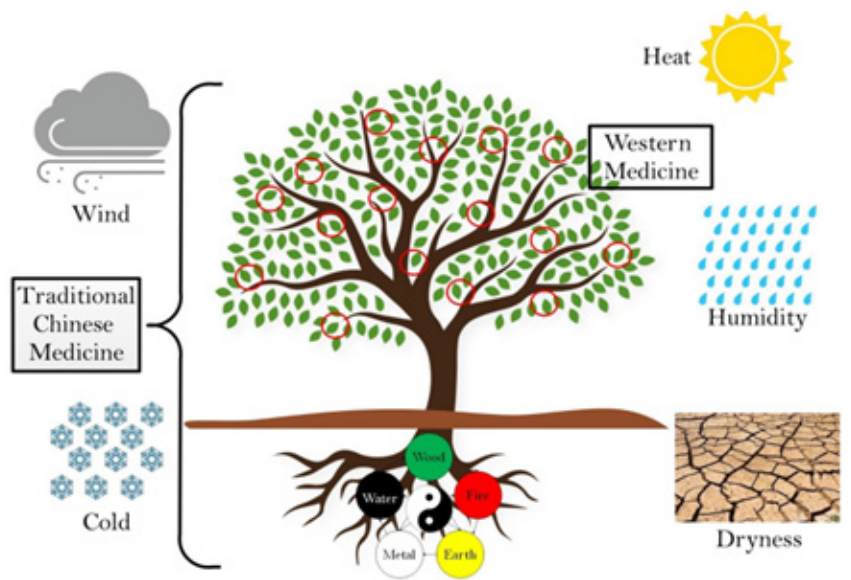

Figure 3 Metaphor of the tree comparing Western and traditional Chinese medicine points of view.

But there are parts of this tree that is not seeing by the naked eyes, represented by the roots that are normally under the earth. In this part, there are two theories in traditional Chinese medicine. The Yin and Yang theory and the Five Elements theory. ${ }^{7-16}$ 
In the TCM perspective, they see the whole tree that represents the whole body and explains the functioning of the human body through a holistic view. They usually see at the same time what they can see and also, what they cannot see, that are the energies that circulate inside the meridians from the root to the leaf and from the leaf to the root. Also, they consider the influences of the external pathogenic factors that are surrounding the tree such as Wind, Cold, Heat, Dryness, Humidity as the possible factor triggering the formation of diseases such as the infections and the influence of wrong eating habits leading to energy disharmony. According to traditional Chinese medicine, all energy imbalances has the emotion as the initial factor to begin and maintain the imbalances of the energy, that is leading to the formation of diseases and may have an influence on wellbeing. In the case of Bell's palsy, the manifestation of the symptom is on the leaf-level on the branch of neurology. The focus in Western medicine is to treat each leaf in each specialty. The part of the tree that is below the earth - invisible to the naked eye - is the roots of the tree. This part remains unknown to Western medicine mainly because its existence is not recognized or discussed in the medical faculties yet but the author is showing through many articles that she is writing, all emphasizing the need to have the two perspectives to better understand the formation of disease and in this way, understand how to treat it accordingly. ${ }^{7-16}$

Before the author explains the case report of how is the physiopathology of the formation of Bell's palsy in the post-partum period, she would like show the reasoning she used to treat all her patients nowadays. This case that became the cornerstone of all treatments of the author started during the treatment of one specific patient in $2006 .^{7-17}$

This patient was an afro-descendent male patient of 70-yearsold, who reported pain in the legs and was using anti-inflammatory medications for six months with no improvement. He sought another kind of treatment using acupuncture. In his first appointment, he was diagnosed with Kidney-Yang deficiency (fells cold in his feet), according to traditional Chinese medicine (TCM). He received treatment with Chinese dietary counseling, acupuncture and auricular acupuncture associated with apex ear bloodletting. ${ }^{7-17}$

With the treatment done, the pain in the legs reduced very much and the patient was submitted to an interview 30 days after this treatment. In this appointment, the patient revealed that his intraocular pressure had also lowered, from $40 \mathrm{mmHg}$ to $17 \mathrm{mmHg}$, confirmed by his ophthalmologist. During the treatment he received by the author, he had not reported to her that he had been treating glaucoma in the last 40 years with only little improvement of his condition, but never his intraocular pressure went down like in this case..$^{7-17}$

This unusual case became the cornerstone of all the studies of the author, and after this case, she is studying how the treatment focused on the root of the problem, that are the energy imbalances, could treat different diseases and symptoms simultaneously and using the same method. ${ }^{7-17}$

In the case of Bell's palsy, particularly in post-partum period, it is important to consider the influence that the tree suffers when exposed to external pathogenic factor. The tree represents the human body, and the influence of the external factors that are generating Bell's palsy is Wind and Cold. ${ }^{18}$

The Wind is one of five external pathogenic factors that characterize the five seasons according to traditional Chinese medicine. The invasion of Wind in the body resembles the Wind in nature; thus, it produces change and acceleration in what otherwise would be steady and slow. When excessive, it might imbalance other energy. Wind attacks the body by penetrating the skin and the pores; an important result in TCM is the emergence of imbalances of external origin caused by climatic aggression pathogenic factors. ${ }^{6}$

Previous scholars, such as Huangdi Neijing states that Wind when in the upper body has a pernicious influence on Yang energy. Because Wind is light and related to the element of Metal, it is believed to influence mainly the upper body, especially the face, skin and sweat glands, and lungs. When the body is invaded from outside, it is because its defensive capabilities are weakened, causing a mismatch in the opening and the closing of the pores in the entire body, leading to the invasion of other pathogenic factors causing diseases with symptoms such as some headaches, nasal obstruction, painful and itching throat, facial edema, abnormal aversion to wind, and perspiration. ${ }^{18,19}$

One of the theories that are in the root level is the theory of Yin and Yang demonstrated in the Figure 4. Yin and Yang are two opposite and complementary forces that exist in our world, in everything, including the human body. A possible example is women and men, day and night, bad and good. ${ }^{7-17}$

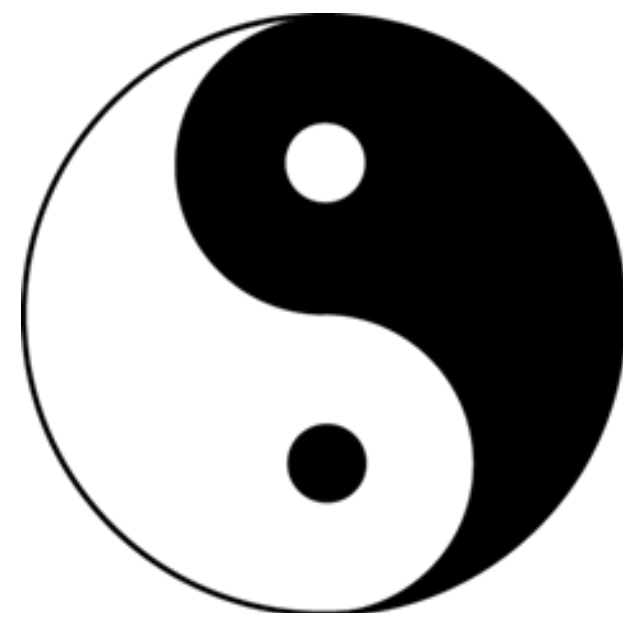

Figure 4 Yin and Yang.

For Yin and Yang energy to flow inside the meridians, $Q i$ and Blood have to work in harmony with them, as the author is showing in the Figure $5 .^{7-17}$
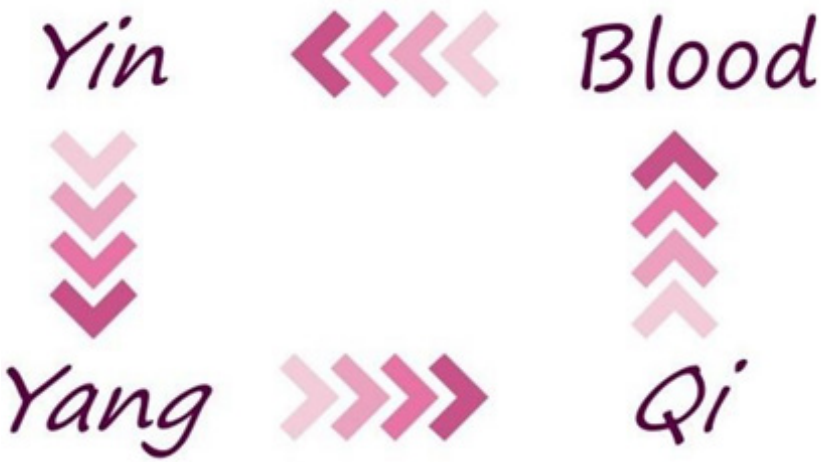

Figure 5 Yin, Yang, $Q i$ and Blood.

Basically, $Q i$ is the energy that circulates throughout your body. ${ }^{7-17}$ Qi moves the Blood that means if $Q i$ stays stagnant long enough, then the body fluids that are flowing begin to stagnate as well..$^{7-17}$

To achieve health, the main aim is to balance these four energy Yin, Yang, $Q i$ and Blood in all the treatment, in any kind of disease. But the author wants to emphasize that when the patient is with fever 
or entrance of external pathogenic factor, the physician needs to take out these external pathogenic factor, before toning the energies, that are deficient, because if the physician tones the internal energy with the external pathogenic factor inside the body, it could worsen the patient's symptoms, instead of improving. This was a chapter of a course of Chinese herbs lecture, made by Dr. Lo Der Cheng in Brazil, author of the book Chinese Masterful Formulas. ${ }^{7-17,20}$

The lack of energy of one of these energies or a combination of them can lead to the formation of internal Heat inside the body, as you can see on the Figure $6 .^{7-17}$

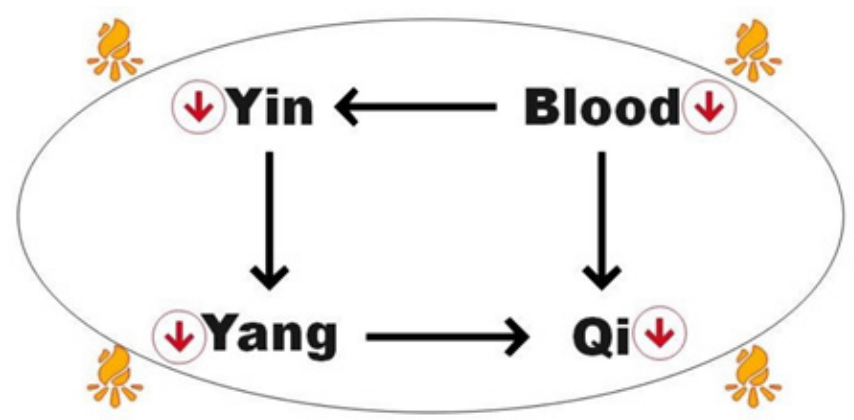

Figure 6 Formation of internal Heat when there is energy deficiency of Yin or Yang or Qi or Blood in one or a combination of two, three energies or all of them.

The Five Elements theory is the second theory that traditional Chinese medicine basis all its reasoning. According to this theory, everything in the world represents one element in the five elements theory, that are Fire, Earth, Metal, Water and Wood, as you can see in the Figure 7. Each massive organ has a hollow organ that they are coupled. In this case, for example, the hollow organ of the Liver is the Gall bladder. The Small intestine is the hollow organ that is coupled to the Heart meridian. The stomach is the hollow organ of Spleen. The Large intestine is the hollow organ that is coupled to Lung and finally, the Bladder is the hollow organ coupled to the Kidney. ${ }^{7-17,21}$

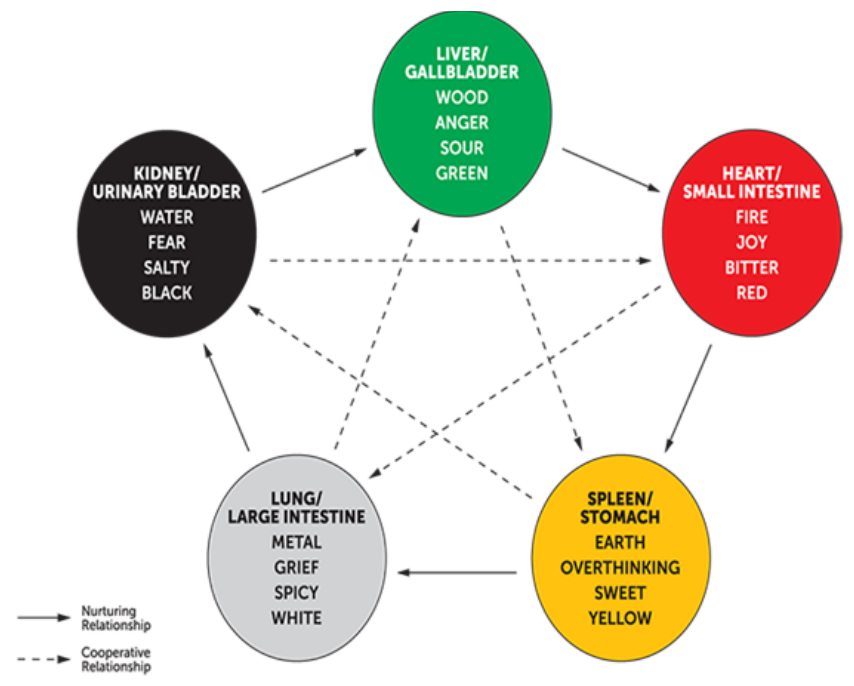

Figure 7 Five Elements theory, the correspondent five elements with the five massive organs and the hollow organ that each massive organ is coupled.

According to some studies published in the literature such as The Geometry of Emotions: Using Chakra Acupuncture and 5-Phase Theory to Describe Personality Archetypes for Clinical Use, written by Christopher R. Chase and published by Medical Acupuncture on February 2018, the author is correlating the chakras' energy centers with the five massive organs that corresponds to the five elements in the Five Elements theory. The correlation between seven chakras' and the five massive organs are described in the Figure $8 .^{7-17,22}$ One element provides energy and control the other elements on Generation and Control cycle.

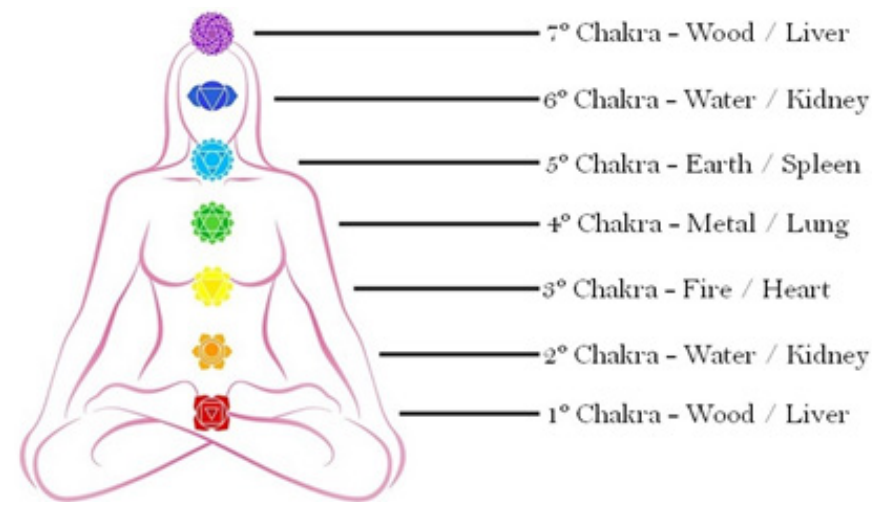

Figure $\mathbf{8}$ Correlation between the seven chakras and the five massive organs in the Five Elements theory.

In the case report described in this article, the patient was diagnosed with chakras' energy deficiencies two years before achieve pregnancy but after she became pregnant, she stopped using the medications to replenish the chakras' energy centers. In the gestational period, there are consumption of energy of the pregnant women for the baby to grow inside her womb and during the delivery process, there are also a huge loss of Yang energy and other energies too such as Blood and $Q i$, leading to a weak state and more propensity of invasion of Wind and Cold, inducing the initial of the formation of some diseases, in this specific case, Bell's palsy. ${ }^{18,23}$

According to traditional Chinese medicine's point of view, when the patient is very deficient in energy, the use of Chinese dietary counseling and acupuncture alone cannot be sufficient to replenish the chakras' energy centers. In China, it is very common to use Chinese herbal therapy to treat this deficient state of the internal massive organs. But the author lives in Brazil and had some difficulties to treat the patients that need the use of Chinese herbal therapy. So, the author begins to learn homeopathy in 2015 and started to write another theory linking homeopathy with traditional Chinese medicine and this article is entitled Constitutional Homeopathy of the Five Elements Based on Traditional Chinese Medicine, published in the Acta Scientific Medical Sciences on July 2020. The medications used in this article to replenish the chakras' energy centers are described in the Table $1 .^{7-17,21}$

Table I Homeopathies and crystal-based medications used to replenish the energy of the chakras' energy centers

\begin{tabular}{|c|c|c|c|}
\hline Chakras & Five elements & $\begin{array}{l}\text { Homeopathy } \\
\text { medications }\end{array}$ & $\begin{array}{l}\text { Crystal based } \\
\text { medication }\end{array}$ \\
\hline$I^{\circ}$ Chakra & Wood/Liver & Phosphorus & Garnet \\
\hline $2^{\circ}$ Chakra & Water/Kidney & $\begin{array}{l}\text { Natrum } \\
\text { Muriaticum }\end{array}$ & Orange Calcite \\
\hline $3^{\circ}$ Chakra & Fire/ Heart & Sulphur & Rhodochrosite \\
\hline $4^{\circ}$ Chakra & Metal/Lung & Silicea & Emerald \\
\hline $5^{\circ}$ Chakra & Earth/Spleen & $\begin{array}{l}\text { Calcarea } \\
\text { Carbonica }\end{array}$ & Blue Quartz \\
\hline $6^{\circ} \mathrm{Chakra}$ & Water/Kidney & Tone $2^{\circ}$ Chakra & Sodalite \\
\hline $7^{\circ}$ Chakra & Wood/Liver & Tone $\mathrm{I}^{\circ}$ Chakra & Tiger Eye \\
\hline
\end{tabular}


The author used homeopathies medications instead of highly concentrated medications to treat patients that have chakras' energy centers, according to Arndt-Schult law. According to this law, created in 1888 , by two German researches, they affirm that when the physician uses any highly concentrated medication, the vital energy of the patient will reduce and the use of these kinds of medications could be harmful for the patient. And when using highly diluted medications, the vital energy could increase and that is why, the author used this kind of medication to treat this patient and in all her patients (Figure 9). ${ }^{7-17,24}$

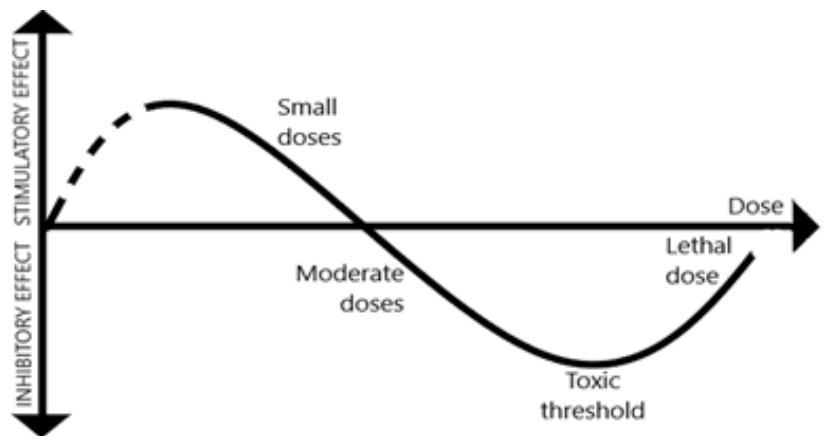

Figure 9 Arndt-Schult law.

In a research the author did in her clinic during the period of 2015 to April 2020, she measured 1000 patient's chakras' energy centers during this period and was able to compile 409 records of these patients. What she found was that 89 percent of the patients that was in treatment in her clinic during this period were in the lowest level of energy, and the Zhen-Qi, that is the ability of the prevent the invasion of external pathogenic factor, in this case, the Wind and Cold, was also compromised in 97 percent of the total analyzed. This article is in process of publication and it is entitled Energy Alterations and Chakras' Energy Deficiencies and Propensity to SARS-CoV-2 Infection that will be published at Acta Scientific Microbiology and also, this data was published at the article entitled Chakras' Energies Deficiencies as the Cause of Dyspnea Post COVID-19 Treatment, published at Journal of Infectious Diseases \& Case Reports on January $2021 .^{25}$

So, the result she had in this research is demonstrating that the majority of the patients that the author is attending in her clinic needs to be treated by highly diluted medications to improve the organic process because as she demonstrated in her study, quite 100 percent of her patients are in the lowest level of energy in any chakras' energy centers. The use of highly concentrated medications in this case could reduce even more the vital energy, that were already low, increasing the chance to have more complications, such as the formation of aggravation of diabetes, hypertension, increasing chance to have myocardial infarction, and many other chronic diseases such as cancer. $^{7-17,25-27}$

To understand better, why the author needs to do all this explanation about theories in traditional Chinese medicine is the necessity to explain to the physician the process involved in the loss of energy after post-partum period. The postpartum is an important moment of women lives, inadequate rest and care of the new mother can lead to a myriad of problems. The issues developed in this period may take years and years to appear; only showing symptoms in menopause and aging. ${ }^{28}$

In TCM, the first 40 days after the birth are considered a time for rest, recovery and seclusion. The only function of the new mother is to take care and feed her baby. ${ }^{28}$
According to traditional Chinese medicine, during the birth, there is an exceptional use of energy. A major part of vital energy, $Q i$ and Yang energy will be applied to bring the baby to the world. The postpartum therefore, is the moment where her energy would be more weaken, and her body would be fragile, being opened to bad energies, emotional and elemental, especially Cold and Wind, as presented by the patient reported in this article, that she needs the use of fan and air conditioning to decrease the sensation of Hot in the body. This patient had before pregnancy, a very cold sensation, meaning that she had Yang deficiency before having Yin deficiency. During pregnancy, it is very common to see women mention that they are feeling hotness in whole body or in the palms and soles because the deficiency of Yang turns to deficiency of Yin, due to consumption of Blood and energy by the baby during the gestational period. As you can see in the Figure 4, the Figure representing Yin and Yang are not static but in dynamic process, one transforming into other and vice versa. ${ }^{7-17,25-28}$

In order to conserve $Q i$, the recommendation according to TCM is that the new mother not forces mind and eyes. The new mother should be orientated to sleep and rest a lot, being able to heal and become strong again. Stressful mental activities should be avoided by her. ${ }^{28}$

As in traditional Chinese medicine and said by Hippocrates, food is medicine and in order to recover and heal her strength faster, they are oriented to eat well. The foods for this period are very nutritive and strong, also in order to produce milk. Meat is generally at the diet center, and most commonly, soups and stews made of bone broths. Broth based soups are a source of iron, calcium, magnesium, protein and contain gelatin which supports the connective tissue repair, and helps stop excessive uterine bleeding. ${ }^{28}$

After the birth, Yin and Yang are unbalanced because woman uses much of her Yang energy on the birth. She has also lost Blood and Qi. The new mother is energetically and physically at her most open. She is considered vulnerable to exterior cold penetration at the same time as being internally cooler. Her Yang must be supported and no cold is allowed near a postpartum woman. Women traditionally used to not to wash their hair for fear of Cold invasion. ${ }^{28}$

That is why in this case reported in this article, where she had Bell's palsy symptom one day after her daughter was born, because she uses fan in her body directly to soften her hot flashes, which were generated by the loss of energy during pregnancy and by the delivery itself. According to the article written by the author entitled Energy Alterations and Chakras Energy Deficiencies in the Pathophysiology of Bell's palsy, published by Journal of Neurology and Experimental Neural Science on May 2020, the author is demonstrating that patients that have Bell's palsy have energy deficiencies on the root level of the tree, showed in the Figure 3, and the treatment of these energy deficiencies is very important to fortify the energies that, it is predisposing the patient to the invasion of Wind and Cold, generated by the lack of energy to prevent this invasion. ${ }^{18}$

But it is not the invasion of Cold and Wind generated by the fan or air conditioning but also, the Cold energy when ingesting raw food because the majority of foods that is raw, has cold energy. In the case of the patient reported in this article, she had a very good evolution of recovering from her face deviation, because despite doing acupuncture sessions, it was also advised her to do not consume raw foods meaning that she needs to cook, saute or bake all the raw foods before eating because even the Cold energy presented in the foods could worsen her case. In this case, it was recommended to cook all fruits and vegetables with exception of lemon, papaya and apple that have neutral energy. ${ }^{18,28,29}$ 
The patient also was orientating to dress with a light clothes to cover her skin from the invasion of Wind and Cold and to protect herself from Cold penetration. ${ }^{18,28}$

The idea of putting ice on the perineum to stagnate the Blood during and after childbirth is absolutely forbidden in Chinese culture. This modern practice of ice is thought to be responsible for painful menstruation, difficult menopause, pelvic pain and even arthritis. ${ }^{28}$

These teachings are rarely explained to patients in Western medicine because, as the author explained earlier, the physicians are still treating patients' symptoms at the leaf level in the metaphor of the tree, as demonstrated in the Figure 3. Western medicine does not yet understand the whole process that occurs at the root of the tree, represented by the Yin and Yang theory and the theory of the Five Elements, the energy imbalances that lead to the formation of diseases, and all this process must be understood at its root level, so that we can deal with and also know how to prevent. Therefore, almost no information is given to pregnant women and their postnatal period regarding the care she should take to avoid Bell's palsy, and also to prevent a wide range of diseases. ${ }^{28}$

The tools used in the treatment of this specific patient described in this article, to treat post-partum Bell's palsy such as acupuncture and homeopathy are both considered medical specialties by the Federal Medical Council since 1995 and 1980 respectively. ${ }^{30}$

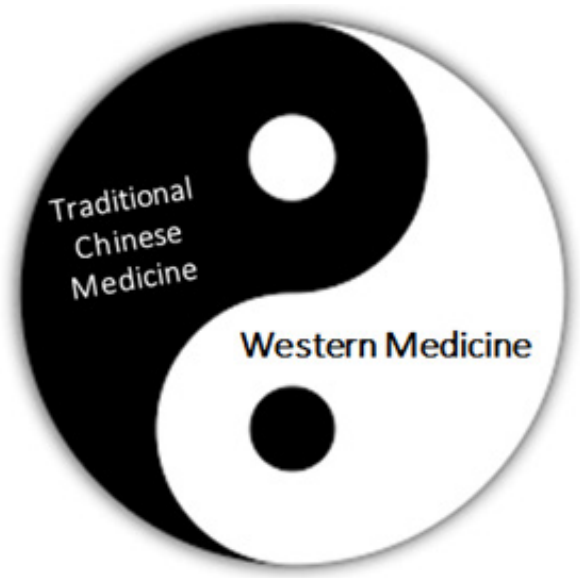

Figure 10 Yin and Yang Metaphor of Western medicine and traditional Chinese medicine.

Nowadays, traditional Chinese medicine and Western medicine are seeing different and used separated by most physicians around the world. But the author wants to demonstrate that they can be integrated. The human body is not constituted only by organs and tissues but all are formed by energy. For this reason, the metaphor of Yin and Yang illustrated in Figure 10 created by the author to symbolize that Western and traditional Chinese medicine are opposites but complementary as well as women and man are opposite but also, complementary. For the adequate treatment of Bell's palsy and the better postpartum period, it is important to associate traditional Chinese medicine and Western medicine reasoning, so the patient can be treated at the leaf level and also the root of the problem, which are the energy imbalances in the internal massive organs or chakras' energy centers. ${ }^{7-17,25-28}$

\section{Conclusion}

Women in the post-partum period has more propensity to develop Bell's palsy because they lost very much Blood and other fluids during the child-birth and usually loose much energy in this process, weakening the body and had more propensity to the invasion of Cold and Wind generation in this form, Bell's palsy symptoms.
The recommendations for the postpartum period is also very important to prevent the formation of diseases due to invasion of external pathogenic factors such as Cold and Wind, and the physician needs to understand what is happening in the body of the patient and what are the causes and the influences of the external pathogenic factor, to prevent the formation of diseases in the post-partum period and after this period, in this case, Bell's palsy.

\section{Acknowledgments}

None.

\section{Funding}

None.

\section{Conflicts of interest}

The author declares that there is no conflict of interest regarding this study.

\section{References}

1. Warner MJ, Julia H, Matthew V. Bell Palsy. Stat Pearls. 2020.

2. Park JM, Kim MG, Jung J, et al. Effect of age and severity of facial palsy on taste thresholds in bell's palsy patients. J Audiol Otol. 2017;21(1):1621.

3. Jessen MR, Shaenboen MJ. Simultaneous bilateral facial palsy in pregnancy. J Am Osteopath Assoc. 1996;96(1):55-57.

4. Zhang W, Xu L, Luo T, et al. The etiology of Bell's palsy: a review. Neurol. 2020;267(7):1896-1905.

5. Yapijakis C. Hippocrates of Kos, the father of clinical medicine, and Asclepiades of Bithynia, the father of molecular medicine. Review. In Vivo. 2009.

6. Dashtdar M, Dashtdar MR, Dashtdar B, et al. The concept of wind in traditional Chinese medicine. J Pharmacopuncture. 2016;19(4):293-302.

7. Huang WL. Auricular acupuncture and Chinese dietary counseling in the treatment of insomnia. Archives of Neurology and Neuro Disorders. 2020;3(1):1-11.

8. Huang WL. Why patients with knee pain still have symptoms despite the use of anti-inflammatory medications. International Journal of Orthopaedics Research. 2020;2(2):21-27.

9. Huang WL. Can hospital osteomyelitis be treated without the use of antibiotics? Microbiol Infect Dis. 2018;2(2):1-6.

10. Huang WL. Could postsurgical nosocomial cellulitis be treated without the use of antibiotics? Acta Scientific Microbiol. 2018;1(9):24-31.

11. Huang WL. How do you treat back pain in your practice? Part 2. Medical Acupunture. 2018;30(1):46-53.

12. Huang WL. Treatment for smoking addiction without the use of any medication. J Pulm Med Resp ther. 2019;2(1):18-27.

13. Huang WL. Why are diabetic patients still having hyperglycemia despite diet regulation, antiglycemic medication and insulin? Int $J$ Diabetes Metab Disord. 2019;4(2):1-14.

14. Huang WL. The importance of chakras and energy imbalances correction in the prevention and treatment of gestational diabetes. ARC Journal of Diabetes and Endocrinology. 2019;5(2):12-20.

15. Huang WL. How can we treat recurrent herpes virus infection without the use of antiviral drugs? Acta Scientific Medical Sciences. 2019;3(8):152159.

16. Huang WL. How to treat low back pain in pregnancy without using any anti-inflammatory medications? Op Acc J Bio Sci \& Res. 2020;2(3). 
17. Huang WL. The importance of correcting energy imbalances and chakras energy deficiencies in the treatment of patients with glaucoma. Clin Res Ophthalmol. 2019;2(2):1-9.

18. Huang WL. Energy alterations and chakras energy deficiencies in the pathophysiology of bell's palsy. Journal of Neurology and Experimental Neural Science. 2020.

19. Maoshing NI. The yellow emperor's classic of medicine: the essential text of Chinese health ahd healing. Shambala, Boston and London; 1995.

20. Lo Der Cheng. Chinese masterful formulas. Roca. 2008

21. Huang WL. Constitutional homeopathy of five elements based on traditional Chinese medicine. Acta Scientific Medical Sciences. 2020;4(7):57-69.

22. Chase C. The geometry of emotions: using chakra acupuncture and 5-phase theory to describe personality archetypes for clinical use. Med Acupunct. 2018.

23. Maciocia G. Obstetrics and gynecology in Chinese medicine. Roca; 2000
24. Leeser O. Support of homeopathy by the Arndt-Schulz law. National Center for Biotechnology Information. 1953.

25. Huang WL. Chakras energy deficiencies as the cause of dyspnea post Coronavirus infection treatment. Journal of Bacteriology and Infectious diseases. Dubai: UAE; 2020.

26. Huang WL. Energy alterations as the underlying cause of primary hypertension. ARC J Nephrol. 2019;4(2):33-44.

27. Huang WL. The importance of correcting energy imbalances in the prevention and treatment of myocardial infarction. Acta Scientific Medical Sciences. 2020;4(6):20-27.

28. Huang WL. What are the sources of fibromyalgia and how to treat it without using anti-inflammatory or anti-depressant drugs? Sci J of Gyne and Obste. 2019;2(2):1-9.

29. Perini M. Chinese Diet Therapy. Livraria e editora Andreoli; 2020.

30. Cremepe. Recognized and sought-after homeopathy and acupuncture. 2006 